\title{
Avicta and Clariva Affect the Biology of the Soybean Cyst Nematode, Heterodera glycines
}

Jared P. Jensen, Department of Plant Pathology and Microbiology, Iowa State University, Ames, IA 50011; Upender Kalwa and Santosh Pandey, Department of Electrical and Computer Engineering, Iowa State University, Ames, IA 50011; and Gregory L. Tylka ${ }^{\dagger}$, Department of Plant Pathology and Microbiology, Iowa State University, Ames, IA 50011

\begin{abstract}
Nematicidal seed treatments are a relatively new strategy for managing plant-parasitic nematodes in row crops. Two such seed treatments, Avicta (abamectin) and Clariva (Pasteuria nishizawae), are marketed by Syngenta for use against Heterodera glycines in soybean production in the upper Midwest. The specific effects of these seed treatments on the biology of the nematode have not been previously reported. The effects of Avicta and Clariva on $H$. glycines hatching, movement, attraction, penetration, development, and reproduction were determined in controlled-

environment experiments. Avicta inhibited juvenile movement and penetration at the seed depth and $3 \mathrm{~cm}$ below the seed. Clariva inhibited juvenile movement and penetration 3 and $5 \mathrm{~cm}$ below the seed and nematode development within the roots of young plants. Both seed treatments affected nematodes in 10- and 20-day-old plants, but effects were not detected on nematodes developing in older plants (30 and 60 days) with larger root systems. These results provide details of the specific mechanisms of earlyseason protection provided by Avicta and Clariva seed treatments.
\end{abstract}

Continued improvement of yield potential through optimization of traits and technology has made seeds the most valuable agricultural input for the soybean farmer. With such a large investment in soybean seed, the agriculture industry has turned its focus to protecting the seed and young seedling against early season diseases and insect damage (Munkvold 2009). Fungicidal, insecticidal, and nematicidal seed treatments are an efficient and cost-effective means to deliver protection against pests and pathogens at the time of planting. Advantages of this approach include a reduced amount of chemical applied per field, continuous early season delivery of chemical within the soil, and fewer nontarget effects, among others. The global seed treatment market has grown from $\$ 1$ billion in 2002 to an estimated $\$ 4$ billion in 2017 (Munkvold et al. 2014).

Traditional soil-applied granular and fumigant nematicides are environmentally hazardous and cost prohibitive for use in large-scale row cropping (Monfort et al. 2006; Zasada et al. 2010). Nematicidal seed treatments are a welcomed new tool for nematode management in soybean production. In the upper Midwest, the soybean cyst nematode, Heterodera glycines Ichinohe, is the principal yield-reducing pathogen of soybeans (Allen et al. 2017). Until a decade ago, the main means of managing $H$. glycines was rotation of nonhost crops and H. glycines-resistant soybean varieties (Niblack and Tylka 2012). Syngenta Crop Protection (Greensboro, NC) has developed two nematicidal soybean seed treatments, Avicta and Clariva, for managing $H$. glycines.

Abamectin, the active ingredient of Avicta, is a small molecule that was known to have nematicidal effectivity as early as the 1980s (Garabedian and Van Gundy 1983; Nordmeyer and Dickson 1985; Sasser et al. 1982). Due to the low water solubility and short half-life of abamectin (Bull et al. 1984; Putter et al. 1981), the compound received little attention in agriculture until it was formulated as

Current address of J. P. Jensen: AgBiome, Research Triangle Park, NC 27709

${ }^{\dagger}$ Corresponding author: G. L. Tylka; E-mail: gltylka@iastate.edu

Funding: We would like to thank Syngenta for providing funding, treated seed, seed treatments, and overall support for this work.

*The $\boldsymbol{e}$-Xtra logo stands for "electronic extra" and indicates that one supplementary figure is published online.

Accepted for publication 13 June 2018.

() 2018 The American Phytopathological Society a seed treatment. As a broad-spectrum chemical nematicide, abamectin has been shown to have activity against Pratylenchus zeae, Meloidogyne incognita, Heterodera schachtii, and Rotylenchulus reniformis (Cabrera et al. 2009; da Silva et al. 2016; Faske and Starr 2006).

Clariva is a biologically based seed treatment containing spores of Pasteuria nishizawae, an obligate, endospore-forming bacterial parasite of $H$. glycines (Sayre et al. 1991). For many years, it was not possible to produce large quantities of Pasteuria for use in fields for nematode biocontrol. But in 2004, Pasteuria Biosciences succeeded in developing a large-scale fermentation process for Pasteuria species (Wilson and Jackson 2013), and subsequently, Syngenta Crop Protection developed and launched the seed treatment Clariva in 2014.

Field-based studies of nematicidal seed treatments are useful to assess if the products affect yields and nematode population densities and to what extent (Barham et al. 2005; Bissonnette et al. 2018; Vitti et al. 2014). But such field studies do not reveal specifically how or when a treatment works. To assess the specific benefits of a seed treatment, controlled-environment experiments are necessary. In this article, our objective was to develop a combination of greenhouse and laboratory assays to study nematode biology. We then used these methods to determine the effects of Avicta and Clariva on specific activities and life stages of $H$. glycines.

\section{Materials and Methods}

We conducted experiments to assess the effects of Avicta and Clariva seed treatments on nematode hatching, movement, attraction, root penetration, development within roots, and reproduction. The first two methods described immediately below explain how $H$. glycines eggs, second-stage juveniles (J2s), and leachates from soil planted with treated seeds were collected. Each subsequent section describes the experiments conducted to test the effects of Avicta and Clariva seed treatments on an individual life stage or process of $H$. glycines. All seed used in the experiments was produced and harvested in 2015. Untreated seed of the varieties used in the experiments were sent to Syngenta personnel in Stanton, MN, where each seed was treated with approximately $0.1 \mathrm{mg}$ of abamectin in Avicta $500 \mathrm{FS}$ solution or $1 \times 10^{7}$ spores of Clariva PN solution. The control solutions used in the hatching, movement analysis, and juvenile attraction experiments consisted of formulated Avicta and Clariva that were received and first opened in 2015.

Nematode egg and juvenile preparation. Populations of $H$. glycines used in laboratory and greenhouse experiments were maintained in greenhouse culture pots on $H$. glycines-susceptible soybeans, Glycine max cv. Williams 82, grown in Fruitfield coarse sand collected from Muscatine, IA, naturally infested with $\mathrm{H}$. glycines 
(HG type 2.5.7). Eggs and second-stage juveniles (J2s) were collected from adult $H$. glycines females exposed on the surface of 30-day-old soybean roots. The adult females were dislodged from soybean roots placed on a $850-\mu \mathrm{m}$-pore sieve nested over a $250-\mu \mathrm{m}$-pore sieve by spraying the roots with a stream of tap water. The adult females collected on the $250-\mu \mathrm{m}$-pore sieve were separated from soil and root debris through sucrose centrifugation using a 1,362 g/liter sucrose solution (Jenkins 1964). Eggs were released by crushing the females using a rotating rubber stopper on the surface of a $250-\mu \mathrm{m}$-pore sieve (Faghihi and Ferris 2000). The eggs then were collected on a 25- $\mu \mathrm{m}-$ pore sieve nested under a $75-\mu \mathrm{m}$-pore sieve. A second round of sucrose centrifugation with $454 \mathrm{~g} /$ /iter sucrose/water solution further separated the eggs from debris (Jenkins 1964). The eggs were rinsed with water on a $25-\mu \mathrm{m}$-pore sieve to remove the sucrose solution and then were used in experiments or were set up for collection of hatched J2s.

To collect $\mathrm{J} 2 \mathrm{~s}$, eggs were placed on a $30-\mu \mathrm{m}$-pore sieve and submerged in a layer of tap water at $25^{\circ} \mathrm{C}$ for $72 \mathrm{~h}$ (Wong et al. 1993). Hatched J2s moved through the pore openings in the sieve into the water below. To obtain active $\mathrm{J} 2 \mathrm{~s}$ for in vitro experiments, hatched $\mathrm{J} 2 \mathrm{~s}$ that were collected after $72 \mathrm{~h}$ were placed on a $30-\mu \mathrm{m}$-pore sieve again and set in a layer of tap water. After one to $2 \mathrm{~h}$, the $\mathrm{J} 2 \mathrm{~s}$ that moved through the sieves were collected in the water below and used for experiments.

Collection of soil leachate. In a polystyrene 6-well microplate (Thermo Fisher Scientific Inc., Waltham, MA), a 30- $\mu \mathrm{m}$-pore sieve containing $6.5 \mathrm{~g}$ of sterile 1:1 sand/soil mixture was placed in each well. Next, one seed of $H$. glycines-susceptible soybean (cv. Williams 82) treated with either Avicta or Clariva was planted in the soil in each sieve in the 6-well plate. Untreated seed and unplanted (fallow) soil were included as controls. Sterile distilled water $(2 \mathrm{ml})$ was added to each sieve. The plates were covered with lids and placed in an incubator for $24 \mathrm{~h}$ at $25^{\circ} \mathrm{C}$ in the dark. Next, $2.5 \mathrm{ml}$ of sterile distilled water was added to each sieve, and the leachate that flowed through the sieve was collected in the well below. Soil leachates from five wells with the same treatment were collected and combined into a sterile $50-\mathrm{ml}$ conical tube and stored at $4{ }^{\circ} \mathrm{C}$ until used. New leachate was collected for each run of the experiments described below.

Hatching experiments. In a sterile, polystyrene 6-well microplate, $3 \mathrm{ml}$ of a single treatment solution was added to each well. Treatment solutions consisted of $500 \mu \mathrm{l}$ of a soil leachate (described above) combined with $2.5 \mathrm{ml}$ of sterile distilled water. Control treatments were $0.1 \mathrm{mg}$ of abamectin in Avicta solution, $1 \times 10^{7}$ spores of Clariva PN solution, sterile distilled water, and $5.5 \mathrm{mM} \mathrm{ZnSO}_{4}$, all made to a final volume of $3 \mathrm{ml}$ with sterile distilled water. Next, a $30-\mu \mathrm{m}$-pore sieve was added to the two left-most wells in each well plate. Each row of the 6-well plate served as an experimental unit. Between 300 and $400 \mathrm{H}$. glycines eggs were added to each sieve. The plates were covered with a lid, sealed with Parafilm, and incubated in the dark at $25^{\circ} \mathrm{C}$. The sieves (containing the unhatched eggs) were transferred to the middle wells of the plate after 3 days and to the right-most wells after 7 days. After each transfer, the plates were recovered, sealed with Parafilm, and incubated in the dark at $25^{\circ} \mathrm{C}$. On the 14th day, the remaining contents of each sieve were washed out with water into a clean, empty well of a new plate. The number of $\mathrm{J} 2 \mathrm{~s}$ that hatched at days 3, 7, and 14 were counted. The number of unhatched eggs from the remnants washed from the sieve on day 14 also was counted. Cumulative percentage hatch was calculated by dividing the total number of hatched juveniles (on days 3, 7, and 14 combined) by the total number of nematodes in the experimental unit (hatched juveniles and unhatched eggs). The experiment was conducted twice with four replications per treatment per run.

Movement analysis experiments. Active J2s in $100 \mu \mathrm{l}$ of water (collected as described above) were incubated in a solution of $500 \mu \mathrm{l}$ of soil leachate (collected as described above) diluted with $500 \mu \mathrm{l}$ of sterile distilled water for $2 \mathrm{~h}$ in $1.5-\mathrm{ml}$ microcentrifuge tubes in the dark at $25^{\circ} \mathrm{C}$. Control treatments consisted of $1-\mathrm{ml}$ solutions of $0.1 \mathrm{mg}$ of abamectin in Avicta solution, $1 \times 10^{7}$ spores of Clariva PN solution, sterile distilled water, and heat-killed J2s in sterile distilled water.

To isolate the $\mathrm{J} 2 \mathrm{~s}$ from the incubation solutions, each treatment was spun at 2,000 $\times g$ for $3 \mathrm{~min}$ in a mini centrifuge (Thermo Fisher
Scientific Inc.) to concentrate the nematodes in a pellet. The top $500 \mu \mathrm{l}$ of treatment solution supernatant was removed, and $500 \mu \mathrm{l}$ of $454 \mathrm{~g} /$ liter sucrose solution was added. Each tube was vortexed to resuspend the nematodes with the sucrose solution, then spun again at 2,000 $\times g$ for $3 \mathrm{~min}$. Clean nematodes were contained in the sucrose supernatant, and debris from the soil leachates were contained in the pellet. The top $500 \mu \mathrm{l}$ of supernatant was removed, added to a new $1.5-\mathrm{ml}$ microcentrifuge tube, and mixed with $500 \mu \mathrm{l}$ of sterile distilled water.

Nematodes incubated in leachates of soil planted with treated seeds and in control solutions were analyzed using motion analysis of individual nematodes described by Jensen et al. (2018). J2s in $30 \mu l$ of suspension from the treatments described above were placed on a microscope slide with coverslip and observed with overhead light microscopy (Leica LED 5000 light attached to Leica M205 C stereoscope) at $63 \times$ magnification $(6.3 \times$ magnification, $10 \times$ eyepiece, and $1 \times$ camera). Images were taken of an individual $\mathrm{J} 2$ every $0.1 \mathrm{~s}$ for $60 \mathrm{~s}$ with a high-speed camera (QICAM 12-bit color fast 1394). Then the images were converted into a video, and individual J2s were subjected to movement analysis using a custom MATLAB program that calculated the speed and change in curvature of tracking points along the nematode body. For each treatment, 8-15 J2s were analyzed at the anterior-most tracking point in each of two experimental runs.

Juvenile attraction experiments. Active J2s (15-60) were added to the center nematode entry port of a microfluidic chemotaxis chip (Supplementary Fig. S1) filled with sterile distilled water, as described by Beeman et al. (2016). Soil leachate (30 $\mu 1)$, collected as described above, was added to a treatment port of a randomly assigned chip (1-14), lane (1-4), and side (left or right) combination. Sterile distilled water was used as the control in the opposite treatment port for each lane. Control solutions tested included $0.1 \mathrm{mg}$ of abamectin in Avicta solution, $1 \times 10^{7}$ spores of Clariva PN solution, $500 \mathrm{mM} \mathrm{CaCl}_{2}$, and $500 \mathrm{mM} \mathrm{KNO}_{3}$. Also, sterile distilled water was added to both ports of one lane in each chip to make sure there was no bias for movement of nematodes to one side of the chip or the other. Once the soil leachate treatments and control solutions were added, the chips were placed in an inverted, square, $10-\mathrm{cm}$ petri dish, sealed with Parafilm, then incubated at $25^{\circ} \mathrm{C}$ in the dark.

After $24 \mathrm{~h}$, the chips were examined under a stereoscope, and the number of $\mathrm{J} 2 \mathrm{~s}$ in each side resting chamber (treatment or control) and in the center nematode entry port was counted. The number of $\mathbf{J} 2 \mathrm{~s}$ in each side of the lane was divided by the total number of J2s in all three areas of the lane to determine percentage. Juveniles found in the treatment resting chamber were considered attracted to the treatment, whereas juveniles in the control resting chamber were considered repelled by the treatment. The percentage of juveniles in the treatment resting chamber was compared with the percentage of juveniles in the control resting chamber to determine if there was a significant treatment effect. There were five to six replications per treatment per run, and the experiment was conducted twice.

Experiments to measure penetration of juveniles at discrete soil depths. Falcon $50 \mathrm{ml}$ conical centrifuge tubes (Fisher Scientific, Waltham, MA) were inverted to stand on the cap, the conical tips of the tubes were removed, and three 3.175-mm-diameter holes were drilled into the sides at 2,5 , and $7 \mathrm{~cm}$ from the top. Once fabricated, the tubes were filled with approximately $50 \mathrm{~cm}^{3}$ of sterile $1: 1 \mathrm{sand} / \mathrm{soil}$. One seed of $H$. glycines-susceptible soybean cv. Williams 82 treated with Avicta or Clariva seed treatment was planted per tube, about $2 \mathrm{~cm}$ deep. Untreated Williams 82 and untreated $H$. glycines-resistant soybean cv. Jack were planted in other tubes as controls.

Each tube was watered initially with $10 \mathrm{ml}$ of tap water. The tubes were arbitrarily arranged in a plastic box, then placed in a growth chamber with $16-\mathrm{h}$ day length, at $50 \%$ humidity, and at $25^{\circ} \mathrm{C}$. Each tube received $5 \mathrm{ml}$ of tap water each day for days 2 through 7 . On the sixth day, approximately 200 active $\mathrm{J} 2$ s suspended in $150 \mu$ l water were pipetted through the predrilled holes to the center of the soil column at one of three soil depths $(2,5$, or $7 \mathrm{~cm})$, and the tubes were incubated for an additional $24 \mathrm{~h}$. On the seventh day, the plants were removed from the tubes, and the roots were washed free of soil and patted dry. The roots were separated from the stems at the soil 
line. The mass of each root system was recorded, roots were frozen for $12 \mathrm{~h}$ at $-20^{\circ} \mathrm{C}$, and then thawed.

To isolate the penetrated $\mathrm{J} 2 \mathrm{~s}$, each thawed root system was cut into 1.5-cm-long pieces and macerated with $75 \mathrm{ml}$ of tap water using a household blender on high for $30 \mathrm{~s}$, similar to what was described by Ruan et al. (2012). The macerated mixture was poured through a $250-\mu \mathrm{m}$-pore sieve nested over a $75-\mu \mathrm{m}$-pore sieve nested over a $25-\mu \mathrm{m}$-pore sieve. The root debris in the $250-\mu \mathrm{m}$-pore sieve was macerated further by pushing the material through the sieve with a rotating rubber stopper (Faghihi and Ferris 2000). The macerated root mixture was flushed with water through the middle $75-\mu \mathrm{m}$ pore sieve, and the released $\mathrm{J} 2 \mathrm{~s}$ were collected on the bottom 25- $\mu \mathrm{m}$-pore sieve.

The number of penetrated $\mathrm{J} 2 \mathrm{~s}$ was counted via microscopic observation and compared among treatments on a per gram of fresh root basis. A proportion was calculated as the number of penetrated nematodes of a treatment at a set location, for a single replication, per gram of root, divided by the average number of penetrated nematodes at that same location of the untreated Williams 82 control per gram of root, over all replications. After this, the proportion of all untreated Williams 82 treatments was set to 1.0 , as previously explained by Halbrendt et al. (1992). Three to four replications were planted for each treated seed and control seed for each run of the experiment, and the experiment was conducted twice.

Experiments to measure total juvenile penetration and development. Cone-tainers with a volume of $150 \mathrm{~cm}^{3}$ were filled with sandy soil naturally infested with $H$. glycines with an initial egg density of 1,500 eggs per $100 \mathrm{~cm}^{3}$. One seed of Williams 82 treated with Avicta or Clariva seed treatments was planted in each Cone-tainer, about $2 \mathrm{~cm}$ deep. Seeds of untreated Williams 82 or untreated Jack were planted as controls. Plants were grown in a growth chamber in 16-h day length, at $50 \%$ humidity, at $25^{\circ} \mathrm{C}$, and watered with $20 \mathrm{ml}$ of tap water every 2 days for 10,20 , or 30 days.

On the designated sample dates, plants were removed from the Cone-tainers and their root systems were carefully dipped in water to remove soil. The stems were removed from the roots at the soil line and discarded, the roots were patted dry, and root mass was recorded. The 30-day-old roots were placed on a $850-\mu \mathrm{m}$-pore sieve nested over a $250-\mu \mathrm{m}$-pore sieve and were sprayed with water to dislodge adult females that were exposed on the root surface. The females were stored in labeled 50-ml conical tubes. Individual root systems were frozen for $12 \mathrm{~h}$ at $-20^{\circ} \mathrm{C}$ then thawed and cut into $1.5-\mathrm{cm}-$ long segments, added to $75 \mathrm{ml}$ of tap water in a household blender, and pulsed on high 10 times, then blended on high for $30 \mathrm{~s}$. The macerated mixture was poured through a stack of sieves with pore sizes $850,250,150,75,45$, and $25 \mu \mathrm{m}$. Almost all of the nematodes collected on each individual sieve were of a single developmental stage because the $H$. glycines life stages are of different sizes (de Boer et al. 1999; Graney and Miller 1982; Raski 1949). Specifically, adult females were captured on the $250-\mu \mathrm{m}$-pore sieve, fourth-stage juveniles on the $150-\mu \mathrm{m}$-pore sieve, third-stage juveniles on the 75- and 45- $\mu \mathrm{m}$-pore sieves, and second-stage juveniles on the 25 - $\mu \mathrm{m}$-pore sieve. The presence of root debris similar in size to third-stage juveniles made it necessary to collect nematodes of that developmental stage on two sieves.

The top $850-\mu \mathrm{m}$-pore sieve was flushed with water 10 times, removed from the stack, and its contents discarded. The second sieve, with $250 \mu \mathrm{m}$ pores, was flushed with water 10 times and the contents were transferred to a 50-ml conical tube. Each subsequent sieve was flushed with water 10 times, then removed from the stack, and its contents transferred to a labeled conical tube. Overall, the nematodes contained within a root were collected in five different tubes based on the sieves on which the macerated mixture was captured. The nematodes obtained from each sieve were then counted under a stereoscope with overhead lighting. Adult females previously collected from 30-day-old roots were combined with the contents recovered from the $250-\mu \mathrm{m}$-pore sieve of the same root system, and these adult female nematodes were counted.

Some of the adult vermiform males may have left the roots and moved into the soil for mating; therefore it was not possible to get a complete count of the number of adult males, and consequently, males were excluded from the tallies. The number of nematodes in a specific life stage was divided by the total number of nematodes found in the entire root system to give a percent distribution of each developmental stage. These percentages then were converted to a proportion, given as the percentage of nematodes in a given life stage, for a single replication (root system), divided by the average percentage of nematodes in the same life stage for all replications of the untreated Williams 82 control. The proportion for all untreated Williams 82 treatments was set to 1.0 , as previously explained by Halbrendt et al. (1992). Five replications were planted for each treatment and control in each run of the experiment, and the experiment was conducted twice.

Female maturity and reproduction experiments. Small and large Cone-tainers $\left(150 \mathrm{~cm}^{3}\right.$ and $600 \mathrm{~cm}^{3}$, respectively) were filled with Fruitfield coarse sand collected from Muscatine, IA, that was naturally infested with $H$. glycines with an initial egg population density of 1,500 eggs per $100 \mathrm{~cm}^{3}$ of soil. One seed of either Jack or Williams 82, treated with either Avicta or Clariva, was planted about $2 \mathrm{~cm}$ deep. Untreated Jack and Williams 82 were planted as controls. One Cone-tainer of each treatment was arbitrarily placed in an 11liter bucket. Small and large Cone-tainers were planted in separate buckets. Construction sand was added to fill the spaces around the Cone-tainers. The buckets were placed in a water bath kept at $25^{\circ} \mathrm{C}$ inside a greenhouse.

Each Cone-tainer was watered with tap water, and the soil was kept moist every day for the first 5 days, then every 2 days until the end of the experiment. Soybean plants were grown in small Cone-tainers for 30 days and large Cone-tainers for 60 days. After 30 days, plants were removed from the small Cone-tainers, and the roots were carefully dipped in water to remove soil adhered to the roots. Each root system was placed onto a $850-\mu \mathrm{m}$-pore sieve nested over a $250-\mu \mathrm{m}$-pore sieve. With a stream of water, adult females exposed on the root surface were removed from the root and collected on the $250-\mu \mathrm{m}$-pore sieve. These females were stored at $4{ }^{\circ} \mathrm{C}$ until counted. Root systems were separated from stems at the soil line and patted dry, and the mass of each root system was recorded.

After 60 days, the contents of the large Cone-tainers were emptied one by one into clean 11-liter buckets. Each bucket was filled with 1 liter of water, and the root systems were carefully dipped repeatedly to remove soil adhered to the roots. Females were removed from roots as described above, stored in labeled containers, and the mass of each root system recorded. Cysts, the dead $H$. glycines females, were extracted from the soil in the bucket. The soil:water mixture in the bucket was stirred clockwise at a constant speed for $20 \mathrm{~s}$ then let sit for $20 \mathrm{~s}$. Next, the suspension was poured through a $850-\mu \mathrm{m}-$ pore size nested over a $250-\mu \mathrm{m}$-pore sieve (Gerdemann 1955). Another 1 liter of tap water was added to the bucket, and the process was repeated once more. Cysts from the soil were collected from the $250-\mu \mathrm{m}$-pore sieve and stored at $4^{\circ} \mathrm{C}$ until counted.

Using a stereoscope with overhead lighting, the number of females and cysts (for the 60-day experiment) were counted for each plant. Next, the females and cysts were crushed using a rotating rubber stopper (Faghihi and Ferris 2000) to release the eggs. Eggs collected on a $25-\mu \mathrm{m}$-pore sieve were stained acid fuchsin (Niblack et al. 1993) and counted.

The number of females and eggs from a single replication was divided by the mass of its root system to standardize nematode numbers for differences in root growth across replications. The number of females per gram of root, number of eggs per gram of root, and number of eggs per female per gram of root were compared for all treatments and controls. For both the 30- and 60-day experiments, there were six replications of each treatment per run with two experimental runs.

Data analysis. All statistical analyses were completed using JMP Pro 13 (SAS Institute, Cary, NC). Analysis of variance (ANOVA, $P=0.05$ ) with a fit model analysis was used to determine significance of effects of treatment solutions for hatching, movement analysis, total juvenile penetration, and reproduction experiments. Treatment and experimental run were included in the analysis when 
experimental run was significant in the effect tests (this includes movement analysis, total juvenile penetration, and reproduction experiments). Significant treatment means were separated using Tukey's honestly significant difference test (HSD, $\alpha=0.05)$. The means tested included percent hatch for the hatching experiment; speed and change in curvature for movement analysis experiments; nematodes per gram of root for total juvenile penetration experiments; and variety and treatment for reproduction experiments. A paired $t$ test was used to determine significant differences $(P<$ 0.05 ) between percent attraction or repulsion to a given treatment in attraction experiments. Proportions for both the spatial penetration and juvenile development experiments were compared against the null hypothesis (proportion is equal to 1.0) through a $t$ test with $\alpha=0.05$.

\section{Results}

Hatching experiments. Overall, an average of $2 \%$ of the juveniles hatched in all treatments by day 3 . Hatching increased in many, but not all, treatments by day 7. Similar hatch was observed on day 14 for all treatments except $\mathrm{ZnSO}_{4}$ (Fig. 1A). Cumulative percent hatch
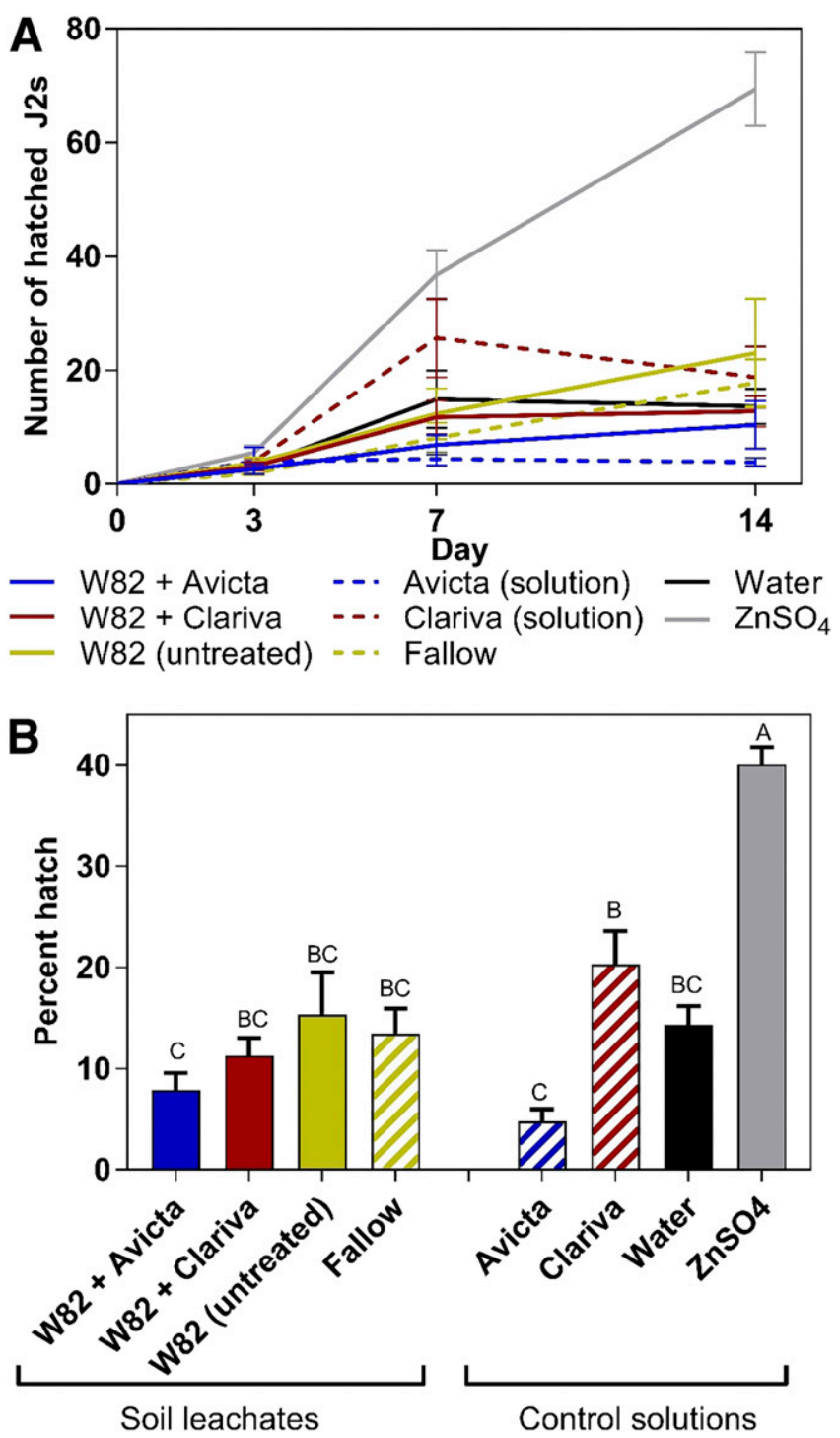

Fig. 1. Hatching of Heterodera glycines in leachates of soil planted with Avicta- and Clariva-treated and untreated Williams 82 (W82) soybean seeds, leachate of unplanted soil, and control solutions. The number of second-stage juveniles hatched was counted at 3,7 , and 14 days (A), and cumulative percentage hatch was calculated at day 14 (B). Letters above each bar indicate differences in cumulative percentage hatch according to Tukey's honestly significant difference test $(\alpha=0.05)$. was greatest in $\mathrm{ZnSO}_{4}$, at $40 \%$, and was lowest in Avicta solution, at $5 \%$ (Fig. 1B). There were no significant differences in cumulative percent hatch of juveniles from eggs incubated in leachates of soil planted with treated or untreated seeds compared with the fallow and water controls.

Movement analysis experiments. The movement of the anterior region of individual $H$. glycines $\mathrm{J} 2 \mathrm{~s}$ was analyzed for two parameters, speed and change in curvature (Fig. 2). The average speed of J2s incubated in water was $1.67 \mu \mathrm{m} / \mathrm{s}$ and $1.39 \mu \mathrm{m} / \mathrm{s}$ in leachate of fallow soil. There were no significant differences in $\mathrm{J} 2$ speed of movement in leachates of soil planted with untreated Williams 82, fallow soil, and the water control. Speed of movement of the J2s was significantly less in leachates of soil planted with seeds treated with either Avicta or Clariva than the water control. Similar treatment effects occurred with change in curvature. The average change in curvature for $\mathrm{J} 2 \mathrm{~s}$ incubated in water was $0.0011 \mu \mathrm{m}^{-1}$ and in leachate of fallow soil was $0.00081 \mu \mathrm{m}^{-1}$. There were no significant differences in change in curvature of $\mathrm{J} 2 \mathrm{~s}$ between those in the water control and in leachates of soil planted with untreated Williams 82 seed and fallow soil, but change in curvature was significantly less in leachates of soil planted with seeds treated with Avicta and Clariva compared with the water control.

Juvenile attraction experiments. Overall, $8-13 \%$ of the juveniles in the experiment moved either toward or away from the treatments. There was significant attraction of $\mathrm{J} 2 \mathrm{~s}$ toward the $\mathrm{KNO}_{3}$ positive control, at $15 \%$. Also, there was significant repulsion of J2s from the $\mathrm{CaCl}_{2}$ negative control, at $7 \%$. There were similar numbers of nematodes in the left and right sides of chips when water was used in both ports of the same lane. And there were no significant differences in $\mathrm{J} 2$ attraction or repulsion for any of the soil leachate treatments or control solutions, with $8 \%$ or less movement of $\mathrm{J} 2 \mathrm{~s}$ toward or away from any specific treatment (Fig. 3).

Experiments to measure penetration of juveniles at discrete soil depths. Of the approximately $200 \mathrm{~J} 2 \mathrm{~s}$ introduced into the soil at each depth, 7-13.5\% penetrated the roots of the untreated Williams 82 control. The average number of nematodes in the roots of the untreated control, by depth, was 14,18 , and 27 for 2,5 , and $7 \mathrm{~cm}$, respectively. The highest number of $\mathrm{J} 2 \mathrm{~s}$ that penetrated a single plant was 59 , and some plants had no nematodes penetrated. Significantly fewer J2s penetrated roots of seedlings grown from Avicta- or Clariva-treated seeds than roots of untreated Williams 82 when inoculated at the seed depth, which was $2 \mathrm{~cm}$ below the soil surface (Fig. 4). Similar significant reductions in penetration were observed when

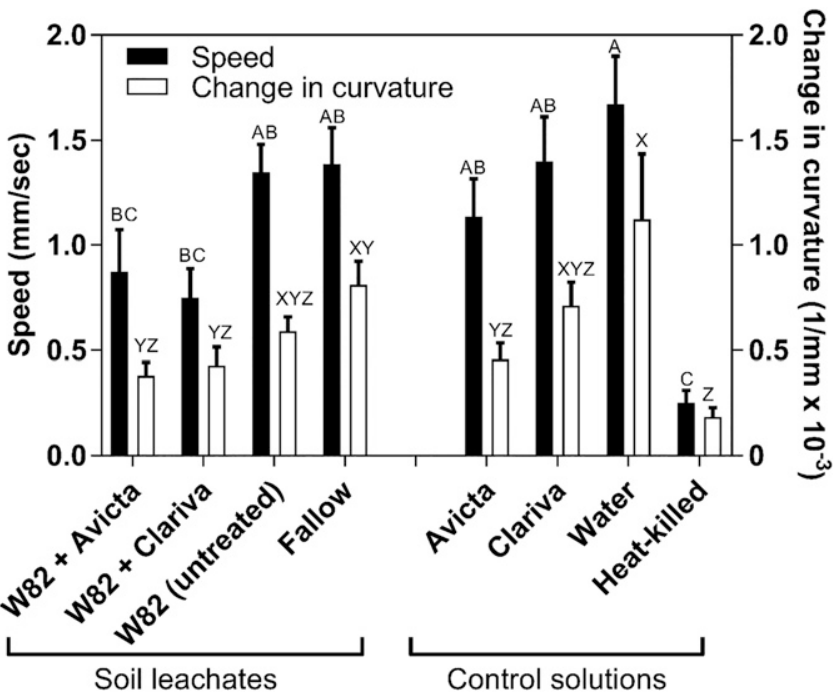

Fig. 2. Movement of Heterodera glycines second-stage juveniles (J2s) after exposure to leachates of soil planted with nematicide-treated soybean seeds was measured by speed (black bars) and change in curvature (white bars) over $60 \mathrm{~s}$ of observation. The speed was analyzed separate from the change in curvature. Letters above each bar indicate differences among speed (ABC) or change in curvature (XYZ) according to Tukey's honestly significant difference test $(\alpha=0.05)$. 
$\mathrm{J} 2 \mathrm{~s}$ were inoculated at $5 \mathrm{~cm}$ deep, which was $3 \mathrm{~cm}$ below the seed. At $7 \mathrm{~cm}$ deep, or $5 \mathrm{~cm}$ below the seed, there were significantly fewer $\mathrm{J} 2 \mathrm{~s}$ in roots of seedlings grown from Clariva-treated seeds relative to those in the untreated Williams 82 roots, but not so for the Avicta treatment.

Experiments to measure total juvenile penetration and development. On average there were 245, 397, and 334 nematodes per gram of root in plants harvested at 10, 20, and 30 days, respectively. There were no differences in the total number of nematodes or the number of nematodes per gram of root among treatments (data not shown). That is, the total number of nematodes per root were not significantly different among Williams 82 treated with Avicta, Clariva, or left untreated, or untreated Jack.

The proportion of $H$. glycines of estimated developmental stages in roots grown from treated seed was compared with that in untreated Williams 82 at days 10, 20, and 30. After 10 days, the average number of nematodes on the untreated control at the $\mathrm{J} 2$ and $\mathrm{J} 3$ life stages was 87 and 156, respectively. There were significantly more (greater proportion) J2s present and significantly fewer J3s on Clariva-treated plants compared with the untreated control (Fig. 5A). There were no differences in nematode development in Avicta-treated plants compared with the untreated control 10 days after planting. At 20 days, the average number of nematodes in the $\mathrm{J} 2, \mathrm{~J} 3, \mathrm{~J} 4$, and adult female stages for the untreated control was $20,457,147$, and 63 , respectively, and there were significantly more $\mathrm{J} 3 \mathrm{~s}$ and significantly fewer adult females in Avicta- and Clariva-treated plants compared with the untreated control (Fig. 5B). After 30 days, the average number of nematodes at the $\mathrm{J} 2, \mathrm{~J} 3, \mathrm{~J} 4$, and adult female stages was $54,122,84$, and 242, respectively, in the untreated control. There were significantly fewer J2s in both Avicta- and Clariva-treated plants than in untreated Williams 82, but similar proportions of nematodes at later life stages (Fig. 5C). Overall, slower development was observed in Avictatreated roots at 20 days and in Clariva-treated roots 10 and 20 days after planting. Differences in proportions of nematodes in different developmental stages were not detected 30 days after planting.

Female maturity and reproduction experiments. There were significant differences in numbers of $H$. glycines adult females and eggs between Jack (H. glycines-resistant) and Williams 82 (susceptible) varieties; therefore, each variety was analyzed separately. The average number of adult females on the untreated Williams 82 control at 30 and 60 days after planting was 136 and 397 females per gram of root, respectively. There were no differences in number of

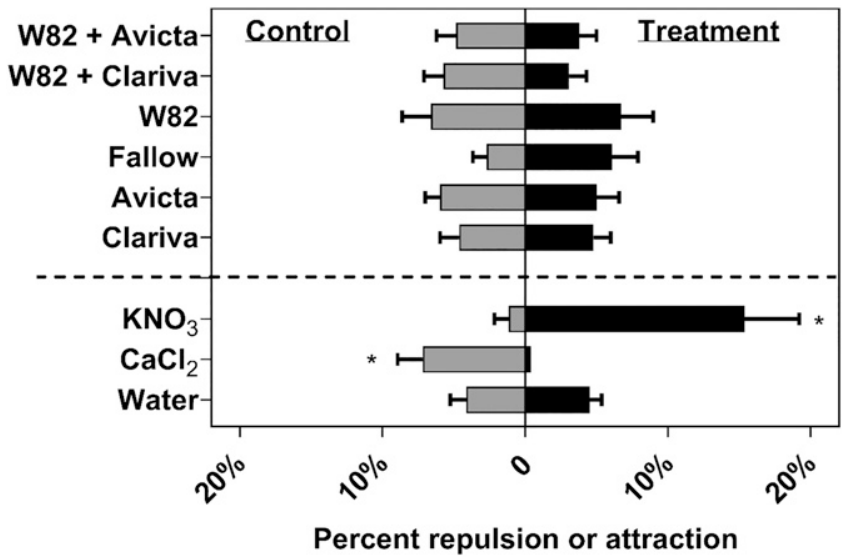

Fig. 3. Percentage of Heterodera glycines second-stage juveniles (J2) that moved toward (attraction) or away from (repulsion) leachates of soil planted with nematicide-treated soybean seeds. Experiments in chips were validated by observing movement in response to leachates of soil planted with untreated seed (W82) and unplanted soil (fallow), $\mathrm{KNO}_{3}$ (positive control), and $\mathrm{CaCl}_{2}$ (negative control). Black bars pointing right indicate the percentage of nematodes in a population that were attracted to a given treatment. Gray bars pointing left indicate the percentage of nematodes in a population that were repelled by that treatment. An asterisk next to a bar indicates significant attraction to or repulsion from the treatment according to a paired $t$ test $(\alpha=0.05)$. females per gram of root in either Avicta or Clariva treatments for either variety at 30 or 60 days (data not shown). The average number of adult females per gram of root on 30-day-old plants was 116 and 119 for Avicta and Clariva treatments on Williams 82, respectively. After 60 days, the average number of adult females was 472 and 427 for Avicta and Clariva treatments on Williams 82, respectively.

When standardized to plant root mass, the average number of eggs per gram of root on the untreated Williams 82 control was 16,232 and 79,648 for 30 and 60 days, respectively. There were no differences in the number of eggs per gram of root between treatments for either variety at 30 and 60 days (data not shown). The average number of eggs after 30 days on Williams 82 was 17,730 and 18,323 for Avicta and Clariva treatments, respectively. After 60 days, the average number of eggs per gram of root was 82,139 and 68,595 on Avicta- and Clariva-treated Williams 82 , respectively. The number of eggs per female per gram of root mass for the untreated Williams 82 control was 62 and 53 at 30 and 60 days, respectively. There were no differences among treatments for either variety at 30 and 60 days.

\section{Discussion}

The seed treatment Avicta significantly affected the most vulnerable life stage of $H$. glycines, the $\mathrm{J} 2$, which mostly exists outside the protection of the soybean root. Significant effects were observed on J2 movement and penetration at several soil depths. In previous experiments, we found that $H$. glycines was sensitive to abamectin at concentrations of 1-10 $\mu \mathrm{g} / \mathrm{ml}$ (Jensen et al. 2018). A similar concentration of $1.56 \mu \mathrm{g} / \mathrm{ml}$ was reported to paralyze $M$. incognita (Faske and Starr 2006). When J2s were incubated in leachate from soil planted with Avicta-treated seed, movement was significantly inhibited. This inhibition likely also occurred when J2s were inoculated on seedlings grown from Avicta-treated seed. Significantly fewer J2s penetrated roots when the nematodes were added near or $3 \mathrm{~cm}$ below the planted seed compared with roots of untreated Williams 82 . However, at $5 \mathrm{~cm}$ below the planted seed, there was no difference in $\mathrm{J} 2$ penetration on Avicta-treated plants compared with roots grown from untreated seed. These results are consistent with results of penetration of $M$. incognita and $R$. reniformis on roots of abamectin-treated cotton (Faske and Starr 2006). Because abamectin

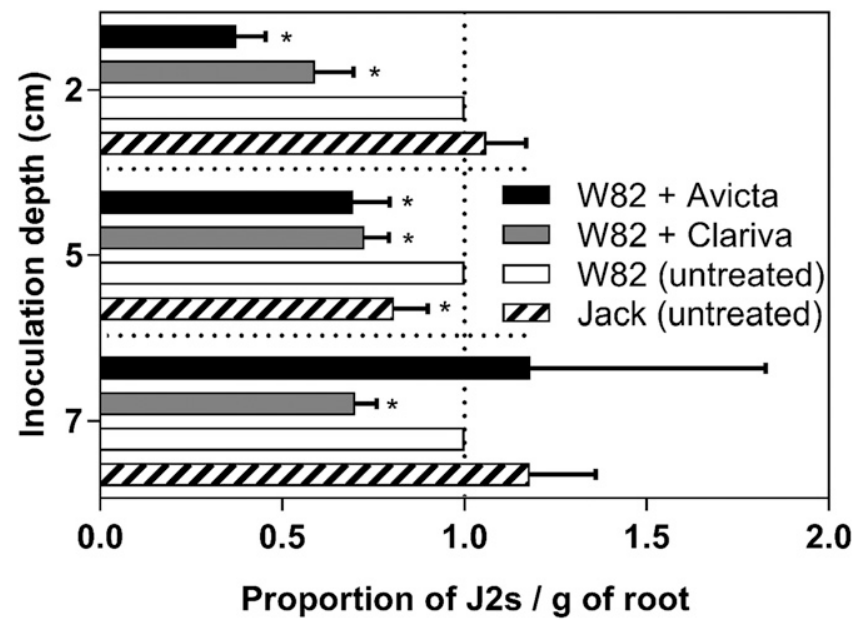

Fig. 4. The number of penetrated Heterodera glycines second-stage juveniles (J2s) on seedlings grown from a nematicide-treated seed was counted $24 \mathrm{~h}$ after inoculation at depths of 2, 5, and $7 \mathrm{~cm}$ below the soil line. Treatments tested were Avicta- and Clariva-treated Williams 82 seeds denoted as W82 + Avicta, W82 + Clariva, respectively. Control treatments included seeds of untreated Williams 82 (W82 untreated) and Jack (Jack untreated). This number was then compared with the average number of penetrated $\mathrm{J} 2 \mathrm{~s}$ on seedlings of untreated Williams 82 , yielding a proportion of penetrated $\mathrm{J} 2 \mathrm{~s}$. The proportion of $\mathrm{J} 2 \mathrm{~s}$ at each depth was calculated by dividing the number of $\mathrm{J} 2 \mathrm{~s}$ per treatment per gram of root by the average number of penetrated J2s per gram of root of the untreated Williams 82 control. Asterisks indicate a treatment is significantly different from the null hypothesis that the proportion is equal to 1 (the same as the untreated Williams 82 control) according to a $t$ test with $\alpha=0.05$. 
has low solubility in water and high affinity for organic matter (Wislocki et al. 1989), it is probable that as a seed treatment, most of the active ingredient will remain near or with the seed coat. It is likely that only small amounts of abamectin move with roots deep in the soil, providing minimal protection from $H$. glycines.

If the effects of Avicta are limited to the upper $3 \mathrm{~cm}$ or so of root systems, this may explain why minimal or no effects were observed in experiments where Avicta-treated plants were grown for 30 days or more. Although the penetrated nematodes developed slower in treated versus nontreated plants 20 days after planting, delayed juvenile development was not detected at 30 days. Avicta also had no effect on the number of adult females or eggs produced on plants grown for 30 and 60 days in our experiments. The 30- and 60-day time frames were enough time for one and two generations of nematodes to occur, respectively. Given the short half-life, high bindingaffinity for soil particles, and limited mobility of abamectin, it is possible that Avicta did not protect larger root systems of plants 30 days or older under our experimental conditions.

We found Avicta seed treatment to have no effect on hatching of H. glycines. That is, hatching in leachates of soil planted with Avictatreated seed was not significantly different than hatching in the water control. However, the $10 \%$ hatch observed for $\mathrm{H}$. glycines eggs in $0.1 \mathrm{mg}$ of abamectin in Avicta solution was comparable to the $20 \%$ hatch observed for Meloidogyne arenaria eggs in $0.1 \mathrm{mg}$ of abamectin B1 (Cayrol et al. 1993). The inability of abamectin to completely inhibit nematode hatching may be explained by the egg shell of $H$. glycines acting as a barrier, protecting developing juveniles from the effects of abamectin, or perhaps the developing juveniles in the eggs may not yet have fully developed nervous systems for the abamectin to affect. Also, perhaps the leachates we used were too dilute, leading to no observed effects.

Clariva contains spores of $P$. nishizawae that attach to the cuticle of the nematode $\mathrm{J} 2$, so it was not unexpected that we saw no effect of Clariva seed treatment on hatching. Like Avicta, Clariva seed treatment significantly affected $H$. glycines $\mathrm{J} 2$ movement, penetration success of $\mathrm{J} 2$ near or 3 and $5 \mathrm{~cm}$ below the treated seeds, and development in young plants 10 and 20 days after planting. The observed decrease in J2 movement after incubation in leachate of soil in which Clariva-treated seeds were planted implies that spore attachment may interfere with nematode mobility. A decrease in $\mathrm{J} 2$ mobility also may explain why significantly fewer nematodes penetrated roots grown from Clariva-treated seeds compared with roots from untreated Williams 82 seeds at all three depths studied $(0,3$, and $5 \mathrm{~cm}$ below the planted seed). The fact that Clariva reduced nematode penetration at $5 \mathrm{~cm}$ below where the treated seed was planted in the soil suggests that the active ingredient may be mobile in the soil. If so, $P$. nishizawae would encounter more nematodes to infect than if it were immobile. The observed decrease in rate of development of $H$. glycines in young plants 10 and 20 days old is most likely due to the penetrated J2s being infected with $P$. nishizawae.

There was no difference in the rate of development of $H$. glycines in roots of plants grown from Clariva-treated seeds compared with the untreated control at 30 days after planting or later. Likewise, there was no observed difference in the total number of penetrated juveniles on whole plants, number of adult females, or number of eggs in these older plants. The lack of effects of Clariva seed treatment in root systems of older plants in our experiments may be attributed to several factors. Environmental conditions in our experiments may have affected the development of $P$. nishizawae within the nematode. Also, not all $H$. glycines hatch at the same time (Niblack et al. 2006), so perhaps a disproportionately high number of Clariva spores attached to the first hatched J2s entering roots, leaving less of an impact on $\mathrm{J} 2 \mathrm{~s}$ that did not hatch right away. These later-hatching J2s may have been successful at parasitizing the roots.

Antagonistic effects of nematicidal seed treatments that repel nematodes from roots could add another layer of protection. In experiments using microfluidic chemotaxis chips, we found that Avicta and Clariva seed treatments neither attracted nor repelled $H$. glycines $\mathrm{J} 2 \mathrm{~s}$. There was lower overall movement of the $\mathrm{J} 2 \mathrm{~s}$ in our attraction experiments $(8-13 \%)$ than Beeman et al. (2016) reported
(32-52\%). So it is possible some treatment effects may have been missed due to lower movement of the J2s in our studies. Still, J2s in the control treatments in our experiments were significantly attracted to $\mathrm{KNO}_{3}$ and significantly repelled from $\mathrm{CaCl}_{2}$ just as reported by Beeman et al. (2016), indicating that our assays were valid. It is likely that Avicta may not diffuse through the microfluidic filters into the lanes of the chemotaxis chips given the insolubility of
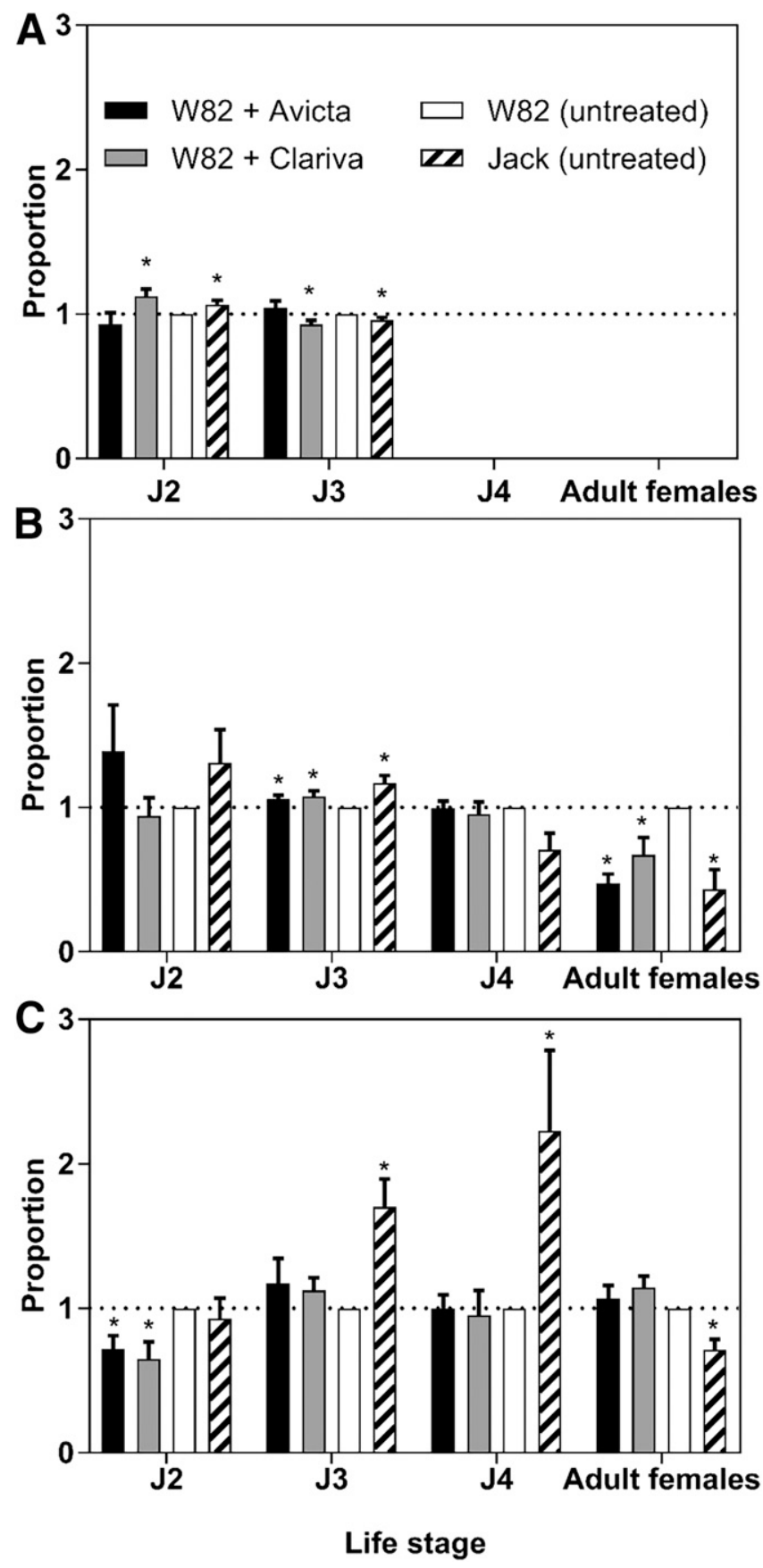

Fig. 5. The proportion of Heterodera glycines in each developmental stage in roots of plants grown from nematicide-treated and untreated seeds at 10 (A), 20 (B), and 30 (C) days after planting. The developmental stages identified were second-stage juveniles (J2), third-stage juveniles (J3), fourth-stage juveniles (J4), and adult females. The number of nematodes in each developmental stage was compared with the untreated Williams 82 control, yielding a proportion of nematodes in that stage, for that treatment. The proportion was calculated by dividing the percentage of nematodes in a given developmental stage by the average percentage of nematodes in that same stage on the untreated Williams 82 control. Asterisks indicate a treatment is significantly different from the null hypothesis that the proportion is equal to 1 (the same as the untreated Williams 82 control) according to a $t$ test with $\alpha=0.05$. 
abamectin in water, resulting in no effect. And spores of $P$. nishizawae are on average $1.9 \mu \mathrm{m}$ wide (Atibalentija et al. 2004) and most likely did not pass through the $1 \mu \mathrm{m}$ width of the filters from the treatment ports into the resting chambers of the microfluidic chips to affect the $\mathrm{J} 2$. Additionally, it is unknown if spores of $P$. nishizawae secrete any exudates that may have been able to diffuse into the lanes of the chemotaxis chip.

Conceptually there are at least three possible scenarios that explain how nematode-protectant seed treatments may adversely affect nematode biology: 1) they may reduce the number of nematodes that enter a root but not affect nematode development after infection; 2) they may affect nematode development within a root but not the number of nematodes that enter a root; or 3) they may affect both nematode penetration and development. Our experiments suggest that Avicta was most effective at reducing the number of nematodes that penetrated roots of younger plants, but had no effect on development (scenario 1 above). Clariva reduced the number of nematodes that entered into the roots and also affected development up to 20 days after planting (scenario 3 above). Neither seed treatment, however, affected the nematode in older plants with larger root systems. To fully understand the effectiveness of Avicta and Clariva seed treatments, more research is needed on the interactions with different environments and the presence of other pathogens.

\section{Acknowledgments}

We would like to thank Dr. Zach Njus and Tajoon Kong for assistance with movement analysis experiments and Dr. Augustine Beeman for help with laboratory and greenhouse experiments.

\section{Literature Cited}

Allen, T., Bradley, C., Sisson, A., Byamukama, E., Chilvers, M., Coker, C., Collins, A., Damicone, J., Dorrance, A., Dufault, N., Esker, P., Faske, T., Giesler, L., Grybauskas, A., Hershman, D., Hollier, C., Isakeit, T., Jardine, D., Kelly, H., Kemerait, R., Kleczewski, N., Koenning, S., Kurle, J., Malvick, D., Markell, S., Mehl, H., Mueller, D., Mueller, J., Mulrooney, R., Nelson, B., Newman, M., Osborne, L., Overstreet, C., Padgett, G., Phipps, P., Price, P., Sikora, E., Smith, D., Spurlock, T., Tande, C., Tenuta, A., Wise, K., and Wrather, J. 2017. Soybean yield loss estimates due to diseases in the United States and Ontario, Canada, from 2010 to 2014. Plant Health Prog. 18:19-21.

Atibalentja, N., Jakstys, B. P., and Noel, G. R. 2004. Life cycle, ultrastructure, and host specificity of the North American isolate of Pasteuria that parasitizes the soybean cyst nematode, Heterodera glycines. J. Nematol. 36:171-180

Barham, J. D., Kirkpatrick, T. L., and Bateman, R. 2005. Field evaluations of Avicta, a new seed-treatment nematicide. Summaries of Arkansas Cotton Research:128-135.

Beeman, A. Q., Njus, Z., Pandey, S., and Tylka, G. L. 2016. Chip technologies for screening chemical and biological agents against plant-parasitic nematodes. Phytopathology 106:1563-1571.

Bissonnette, K. M., Marett, C. C., Mullaney, M. P., Gebhart, G. D., Kyveryga, P., Mueller, T. A., and Tylka, G. L. 2018. Effects of Clariva Complete Beans seed treatment on Heterodera glycines reproduction and soybean yield in Iowa. Plant Health Prog. 19:1-8.

Bull, D. L., Ivie, G. W., MacConnell, J. G., Gruber, V. F., Ku, C. C., Arison, B. H., Stevenson, J. M., and VandenHeuvel, W. J. A. 1984. Fate of avermectin B1a in soil and plants. J. Agric. Food Chem. 32:94-102.

Cabrera, J. A., Kiewnick, S., Grimm, C., Dababat, A. A., and Sikora, R. A. 2009. Efficacy of abamectin seed treatment on Pratylenchus zeae, Meloidogyne incognita, and Heterodera schachtii. J. Plant Dis. Prot. 116:124-128.

Cayrol, J. C., Djian, C., and Frankowski, J. P. 1993. Efficacy of abamectin B1 for the control of Meloidogyne arenaria. Fundam. Appl. Nematol. 16:239-246.

da Silva, M. P., Tylka, G. L., and Munkvold, G. P. 2016. Seed treatment effects on maize seedlings coinfected with Fusarium spp. and Pratylenchus penetrans. Plant Dis. 100:431-437.

de Boer, J. M., Yan, Y., Wang, X., Smant, G., Hussey, R. S., Davis, E. L., and Baum, T. J. 1999. Developmental expression of secretory $\beta$-1,4-endoglucanases in the subventral esophageal glands of Heterodera glycines. Mol. Plant-Microbe Interact. 12:663-669.

Faghihi, J., and Ferris, J. M. 2000. An efficient new device to release eggs from Heterodera glycines. J. Nematol. 32:411-413.

Faske, T. R., and Starr, J. L. 2006. Sensitivity of Meloidogyne incognita and Rotylenchulus reniformis to abamectin. J. Nematol. 38:240-244.

Garabedian, S., and Van Gundy, S. D. 1983. Use of avermectins for the control of Meloidogyne incognita on tomatoes. J. Nematol. 15:503-510.

Gerdemann, J. W. 1955. Relation of a large soil-borne spore to phycomycetous mycorrhizal infections. Mycologia 47:619-632.

Graney, L. S. O., and Miller, L. I. 1982. Comparative morphological studies of Heterodera schachtii and H. glycines. Pages 96-107 in: Nematology in the Southern region of the United States. Southern Cooperative Series Bulletin 276. Fayetteville, AR, USA.

Halbrendt, J. M., Lewis, S. A., and Shipe, E. R. 1992. A technique for evaluating Heterodera glycines development in susceptible and resistant soybean. J. Nematol. 24:84-91.

Jenkins, W. 1964. A rapid centrifugal-flotation technique for separating nematodes from soil. Plant Dis. Rep. 48:692.

Jensen, J. P., Beeman, A. Q., Njus, Z. L., Pandey, S., and Tylka, G. L. 2018. Movement and motion of soybean cyst nematode, Heterodera glycines populations and individuals in response to abamectin. Phytopathology 108: 885-891.

Monfort, W. S., Kirkpatrick, T. L., Long, D. L., and Rideout, S. 2006. Efficacy of a novel nematicidal seed treatment against Meloidogyne incognita on cotton. J. Nematol. 38:245-249.

Munkvold, G. P. 2009. Seed pathology progress in academia and industry. Annu. Rev. Phytopathol. 47:285-311.

Munkvold, G. P., Watrin, C., Scheller, M., Zeun, R., and Olaya, G. 2014. Benefits of chemical seed treatments on crop yield and quality. Pages 89-103 in: Global perspectives on the health of seeds and plant propagation material, Plant Pathology in the 21st Century. Springer, Netherlands. https://doi.org/10.1007/ 978-94-017-9389-6_7

Niblack, T. L., Heinz, R. D., Smith, G. S., and Donald, P. A. 1993. Distribution, density, and diversity of Heterodera glycines in Missouri. J. Nematol. 25:880-886

Niblack, T. L., Lambert, K. N., and Tylka, G. L. 2006. A model plant pathogen from the kingdom Animalia: Heterodera glycines, the soybean cyst nematode. Annu. Rev. Phytopathol. 44:283-303.

Niblack, T. L., and Tylka, G. L. 2012. SCN Management Guide, 5th Ed. Plant Health Initiative. North Central Soybean Research Program. http://www. soybeanresearchinfo.com/pdf_docs/SCNGuide_5thEd.pdf

Nordmeyer, D., and Dickson, D. W. 1985. Management of Meloidogyne javanica, $M$. arenaria, and $M$. incognita on flue-cured tobacco with organophosphate, carbamate, and avermectin nematicides. Plant Dis. 69:67-69.

Putter, I., MacConnell, J. G., Preiser, F. A., Haidri, A. A., Ristich, S. S., and Dybas, R. A. 1981. Avermectins: Novel insecticides, acaricides and nematicides from a soil microorganism. Experientia 37:963-964.

Raski, D. J. 1949. The life history and morphology of the sugar-beet cyst nematode, Heterodera schachtii Schmidt. Phytopathology 40:135-152.

Ruan, W., Zhan, L., Xiao, W., and Chen, S. 2012. An improved method for quantification of Heterodera glycines in plant tissues. Nematropica 42: 237-244.

Sasser, J. N., Kirkpatrick, T. L., and Dybas, R. A. 1982. Efficacy of avermectins for root-knot control in tobacco. Plant Dis. 66:691-693.

Sayre, R. M., Wergin, W. P., Schmidt, J. M., and Starr, M. P. 1991. Pasteuria nishizawae sp. Nov., a mycelial and endospore forming bacterium parasitic on cyst nematodes of genera Heterodera and Globodera. Res. Microbiol. 142:551-564.

Vitti, A. J., Neto, U. R. R., da Araujo, F. G., Santos, L. C., Barbosa, K. A. G., and da Rocha, M. R. 2014. Effect of soybean seed treatments with abamectin and thiabendazole on Heterodera glycines. Nematropica 44:74-80.

Wilson, M. J., and Jackson, T. A. 2013. Progress in the commercialization of bionematicides. BioControl 58:715-722.

Wislocki, P. G., Grosso, L. S., and Dybas, R. A. 1989. Environmental aspects of abamectin use in crop protection. Pages 182-200 in: Ivermectin and Abamectin. Springer, New York, NY.

Wong, A. T. S., Tylka, G. L., and Hartzler, R. G. 1993. Effects of eight herbicides on in vitro hatching of Heterodera glycines. J. Nematol. 25:578-584.

Zasada, I. A., Halbrendt, J. M., Kokalis-Burelle, N., LaMondia, J., McKenry, M. V., and Noling, J. W. 2010. Managing nematodes without methyl bromide. Annu. Rev. Phytopathol. 48:311-328. 